\title{
Symbolic meanings and e-learning in the workplace: The case of an intranet-based training tool
}

\author{
Marina P Michalski \\ University of Essex, UK \\ mmichal@essex.ac.uk
}

\begin{abstract}
This article contributes to the debate on work-based e-learning, by unpacking the notion of 'the learning context' in a case where the mediating tool for training also supports everyday work. Users' engagement with the information and communication technology tool is shown to reflect dynamic interactions among the individual, peer group, organizational and institutional levels. Also influential are professionals' values and identity work, alongside their interpretations of espoused and emerging symbolic meanings. Discussion draws on pedagogically informed studies of e-learning and the wider organizational learning literature. More centrally, this article highlights the instrumentality of symbolic interactionism for e-learning research and explores some of the framework's conceptual resources as applied to organizational analysis and e-learning design.
\end{abstract}




\section{Keywords}

Adult learning theory, identity work, interpretivism, power, symbolic interactionism, workplace e-learning

\section{Introduction}

The spread of innovative information and communication technology (ICT)mediated training initiatives within organizations has spurred increasing academic interest in the field (Macpherson et al., 2005; Sparrow, 2000, 2001). The focus of research into computer-supported collaborative learning (CSCL) has shifted towards socially orientated understandings of instructional tools and processes (Koschmann, 1996). In parallel, themes such as culture, identity, locus of power and social interactions have been explored within wider education research and are slowly being incor- porated into work-based e-learning research (Alavi and Gallupe, 2003; Billett, 2002; Illeris, 2003; Macpherson et al., 2004; Tynjälä and Häkkinen, 2005). However, criticism of the prevalent main- stream bias towards technical and functional aspects of e-learning indicates that a socially orien- tated perspective within that field has not yet been fully articulated and requires further exploration (Govindasamy, 2002; Macpherson et al., 2005; Maule, 1997; Rumble, 2001).

The purpose of this article is to contribute to this growing field of interest and, more specifi- cally, to unpack the notion of the learning context, which is a particularly underdeveloped sub- theme within e-learning research. Much of the debate on 'the context' of e-learning is still limited to addressing the shift 
from bricks-and-mortar classrooms to virtual learning environments, while true contextualization of learning requires the understanding of historical, social, moral, economic and political dimensions and interests (Reynolds, 1997). A number of studies investi- gate changing tutor/learner and learner/group interactions and the effectiveness of novel types of resources as applied to distance or blended learning modes of instruction (Good, 2001; Haythornthwaite, 2000; Jung and Rha, 2000; Maule, 1997; Smith and Newman, 1999; Oliver et al., 2007; Rovai, 2002; Rumble, 2001; Salmon, 2000; Sandelands and Wills, 1996). What now requires further consideration is how learning processes are affected by a much more complex ecology of knowledge acquisition and development in the workplace, as illustrated in the following quote:

... the future of e-learning is in the integration of information management (including training content material, the learner's current knowledge, and the learner's training activities, often now distinctly referred to as content management, knowledge management, and learner management systems), performance support, peer collaboration, and training systems. For example, in the future, a sales employee should be able to use a single intranet portal to collect information about potential customers, find a quick answer to a customer query, interact with other sales staff throughout the country, and take a class about sales techniques. (Welsh et al., 2003: 255)

The case of QA Experts, presented in this study, exemplifies the degree to which the training and knowledge management functions envisioned in this quote are integrated. QA Experts offer quantity surveying services in building 
projects and ongoing fixed assets management and maintenance, focusing on guaranteeing compliance with legal, quality and safety standards, alongside achieving cost-effectiveness throughout a physical asset's life. The company has grown into a global organization via a steep process of acquisitions and now offers full-cycle asset management services from 40 wholly owned offices worldwide, with over 3000 staff, and a $£ 200 \mathrm{~m}+$ turnover. QA Experts' early career learning and development scheme is directly engaged with quantity surveyors' pursuit of chartered status granted by the highly respected Royal Institution of Chartered Surveyors (RICS). The training process takes up to 3 years and provides face-to-face and ICT- mediated training, enabled by a locally developed system, namely, the service delivery system (SDS). The system has dual purpose, in that it is used both for young quantity surveyors' training and for wider knowledge management functions among more experienced core workers.

The main contribution resulting from the analysis of that case lies in exploring technology-mediated learning at work through a symbolic interactionist lens, alongside an interpretivist approach to analysis. This article highlights the instrumentality of symbolic interactionism (SI) in foregrounding the impact of emerging symbolic meanings on the dynamics and outcomes of workbased e-learning initiatives. A central conclusion is that interactions with tools that mediate formal learning and training programmes are susceptible to wider work and power relations. E-learning artefacts are intentionally and unintentionally imbued with symbolic meanings generated in the practice of everyday work. A more complex understanding of the learning context must therefore take this into account, so that the planning, introduction and ongoing 
adaptation of formal training and e-learning programmes can indeed become context-sensitive.

The first part of this article will provide a background discussion of complementary and evolving strands of SI as a framework for analysis. Some of those concepts will then be used to highlight unresolved issues relating to learning and ICT-mediated training in organizations. Following that, the literature review will be extended by juxtaposing concepts deriving from pedagogically informed studies and the organization studies tradition, and the research questions will be refined. After a short introduction to the methods used, the case will then be presented and discussed.

\section{Background}

\section{Investigating ICT-enabled learning processes via SI}

SI has increasingly been applied to studies in a variety of professional fields, including education (Fine, 1993). However, except in a few studies, it remains an underutilized framework within research into computerization in organizations (Prasad, 1993).

Yet, SI provides a useful lens to explain people's interpretations and relationships within their work: symbolic meanings influence individuals' sensemaking and enactments of technology, as well as organizational-level action with respect to the adoption of new tools and systems (Prasad, 1993). Meanings attributed to a variety of objects are influential in a number of ways: establishing value and symbolizing status, mediating claims to knowledge, 
enabling individual association with a field of practice, articulating and reinforcing cultural values and ultimately mobilizing action and commitment (see Swan et al., 2007 for a discussion of Barley and Tolbert, 1997; Bechky, 2003; Bijker et al., 1987; Lamertz et al., 2003; Weick, 1979). At the same time, identity work may lead to the creation of knowledge and status boundaries and resistance to change (Antonacopoulou and Chiva, 2007; Czerniewiecz and Brown, 2010; Fine, 1993; Goodyear and Ellis, 2010).

A variety of conceptual resources arising from a symbolic interactionist framework prove instrumental in shedding light on such complex dynamics. SI as a research programme is multifaceted and still evolving (Fine, 1993; Hallett et al., 2010; Musolf, 1992; Stryker, 2008). In its early phase, Mead (1934), Blumer (1969) and Hughes (1951) focused on the constitutive role of individuals and rebelled against an 'un-peopled' view of institutions and society (Hallett et al., 2010: 488). For early interactionists, workers' interpretations of their work and related objects were central to how they identified with work, how they developed a sense of self and how evolving meanings informed their behaviour and interaction with others (Hallett et al., 2010). Moreover, work artefacts are not fixed, independent entities, but social objects: the meaning of each object - and therefore how they are used - can change according to each individual's interpretation of cues produced in interaction with others. Social objects, then, will be used either reflexively, when individuals 'talk to self', or to mediate communication with others (Charon, 2001: 44-49). These remain pivotal assumptions for ongoing developments of the SI perspective as a whole.

A later wave of work - the Second Chicago School - is described by 
Fine(1993) as a more cynical phase, though still engaged with the aim of 'peopling of institutions' in analysis. Individuals are seen to develop strategies of resistance, whereby they manipulate social objects to create and avoid certain labels and status, thereby escaping a diminished sense of self (Fine, 1993). Goffman's dramaturgical view reworked Cooley's concept of the 'Looking Glass-Self' and is intimately connected with the theme of identity work, whereby individuals continuously recreate desired conceptions of their own work and identity (Goffman, 1959 cited in Fine, 1993; Scheff, 2005). Within a symbolic interactionist rationale, symbolic meanings emerging from interactions within actors' environments support them in validating their own identity and establishing their own self-meanings through choices in light of relationships, situations and local cultures (Fine, 1993; Stryker, 2008). SI core concepts are also instrumental in investigations of ongoing changes to meanings attached to objects and related actions: their meanings are defined and redefined in interactions, in consonance with the use that they have for people at different moments in time (Charon, 2001).

Conduct, coordination and social order are also re-enacted or redefined amid negotiations and processes of role-making and role-taking - always underlined by conflicting personal interests, role- and group-based interests and uneven distributions of power (Hewitt, 2007). Moreover, power dynamics is not only about negotiations and interests but also about locally evolving conceptions of legitimacy: power and legitimacy are intimately interconnected in practice (Hallett, 2003). Legitimacy derives from multiple audience interpretations and evaluations of what constitute legitimate practices, and once individual actions and practices are interpreted as 
legitimate, they acquire 'symbolic power' - that is, the power to define situations (Bourdieu, 1991 cited in Hallett, 2003). Recursively, symbolic power enables individuals to influence perceptions of legitimacy. Ultimately, interpretations of what constitutes power and legitimacy will play a role in the formation of negotiated orders (Strauss et al., 1963), albeit in a contested and provisional manner. That process, however, will be particularly enabled - or hindered - by those social objects and symbols, which have achieved greater 'sedimentation of meanings' throughout time, and therefore are more enduring and powerful than others (Fine, 1992).

In line with this, Stryker's structural SI goes beyond the local and the provisional. This view highlights the power of longer standing social structures and institutions, albeit interweaving identity theory with it (Stryker, 1968, 2008). Stryker sees self and organizations as being shaped by intermediate structures or institutions, such as schools, social networks and associations. Such intermediate structures, in turn, incorporate and reproduce macro-level social structures such as class, gender and ethnicity, with agency being exercised via role and identity choice. From this perspective, individuals have multiple identities that are linked to various roles and activated as required by interactional commitments (Stryker, 2008).

Such concepts are useful in explaining learners' interactions with the ICT tool studied in this article. They also inform interesting questions relating to the recursive interactions between meanings generated at work and the meanings developing within structured learning or training practices. For instance, how can we understand Stryker's (2008) contention that individuals activate specific identities in line with the demands of the task at hand? Can we assume 
that professionals can invoke their worker and learner personas separately, each with different commitments and goals, even if the social context and place of working and learning are the same? How are ICT objects utilized in professionals' own identity work when working and training overlap? It follows that it is not sufficient to study work-based e-learning processes and ICT-mediated work in organizations as two independent dimensions of organizational life. Interactions between the two spheres of activity need to be conceptualized further.

The case will also highlight the role of intermediate institutions, such as the chartered institute's professional standards, and ever more stringent benchmarks for risk management with respect to professional indemnity insurers. What emerges as an important issue - and possibly a source of tension among different strands of SI - is how negotiated orders emerge out of local interpretations, interactions and individual agency against the backdrop of powerful institutional players. In parallel, how do such players affect the interactions between the perceived legitimacy of learning approaches and the emergence of symbolic power? How should we understand the concept of symbolic power within this context? What does 'power to define situations' actually mean within shape-shifting contexts for working and learning? And finally, when work and learning intermingle, how do we unpack the relationship between different layers of perceived legitimacy, for example, work practices and learning and training approaches, and what constitutes legitimate knowledge within wider professional and industrial settings? 
What transpires from this review so far is that SI as a bundle of intellectual resources has the potential to sensitize researchers towards a number of pertinent facets of learner interactions with ICT tools and their working context. Conversely, the very thought of applying SI concepts to a developing phenomenon - in this case, e-learning and training within the workplace raises interesting theoretical questions and offers the opportunity to extend some of that framework's underlying concepts.

\section{Unbundling the context: pedagogical and social perspectives on workplace e-learning}

Further unresolved issues arise from a selective review of a growing body of pedagogically informed studies. Recursive interactions and processes of transferring and transforming knowledge and experience among individuals also have implications for their cognitive development (Koschmann, 1996; Lave, 1988; Nicolini and Meznar, 1995). Planning and design of work-based e-learning initiatives, therefore, must not overlook the pedagogical dimension (Macpherson et al., 2005). There has been some debate on how emerging technologies may enable pedagogically sound training initiatives, in which there is a greater focus on the learner's experience, allowing for a feeling of learner ownership, alongside reciprocity, dialogic reflection and a processual focus (Hughes, 2010). Pivotal to a pedagogically informed approach to elearning design is the prioritization of learners' specific needs, whereby generic off-the-shelf packages give way to programmes which are sensitive to individual learners and their context; which enable virtual face-to-face 
collaboration; and which allow for more sensory modes of interaction such as storytelling, writing and acting (Macpherson et al., 2005).

Furthermore, within pedagogical thinking, the andragogic stance is the perspective that relates most closely to the phenomenon of formal workplace learning. Andragogy focuses on the needs of adult learners and argues for their empowerment and engagement as co-producers of the instructional material and experience, which would entail joint planning and a clear bias towards a problem-solving orientation. It is also recommended that particular attention is paid to learners' prior knowledge and qualifications, their personal and social characteristics, preferred learning styles, intrinsic motivation and readiness for learning (Beetham and Oliver, 2010; Dewald, 2003; Govindasamy, 2002; Knowles, 1995). E-learning designers should also consider learners' personal beliefs and values and their impact on individual motivation (Sharpe and Beetham, 2010).

However, leveraging individual motivation and readiness for learning is not always straightforward: assumptions about a self-reliant and self-motivated learner emerge as problematic (Macpherson et al., 2004). Given that individual learning requirements are affected by the characteristics and decision-making needs of the task at hand (Lahn, 2004), it seems wiser to explore worker learning dispositions as contingent on organizational demands, rather than as fixed individual attributes. Can learner readiness and motivation be considered a purely individual matter, isolated from organizational dynamics? There is growing awareness of the impact of a wider net- work of stakeholders and players on actual learner empowerment and therefore on the quality of the learning experience and outcomes. 
Conflicting stakeholder interests arise when designing training initiatives and tools, and the tensions underlying formal employee development programmes, line manager involvement and staff needs may affect the acceptance of tools and initiatives and attitudes to knowledge sharing (Macpherson et al., 2005; Netteland et al., 2007).

Corporate goals and established sub-systems also play a role in restricting the degree to which individual learners are allowed to engage with the instructional design process. For instance, corporate strategy necessarily underlines corporate university models and priorities (Fresina, 1997; Macpherson et al., 2005). Learning contexts have a political dimension, which conditions 'how workplaces afford individuals or cohorts' the opportunities to participate (Billett, 2002: 57). In addition, this process is populated by a whole ecology of influential actors: mentors, staff developers, technology specialists, colleagues, communities-of-practice and artefacts (Sharpe and Oliver, 2007). However, in practice, there is little real willingness of powerful stakeholders to engage users and other actors with all stages of ICT-mediated learning systems development: user choice is normally restricted to adoption or rejection of any specific tool (Carr-Chellman and Savoy, 2004). A pertinent question, in fact, is whether formal learning and training designers in organizations can actually afford to relinquish control to learners, given the discourse of knowledge-based competitive advantage of corporations, alongside the institutionalization of benchmarking within specific industries (Alvesson and Kärreman, 2001; Francis and Holloway, 2007; Grant, 1996). The organizational quest for control over their strategic knowledge assets, therefore, may explain why the discourse of learner 
empowerment often translates simplistically into course evaluations, instead of in-depth investigations into how learners actually use, perceive and experience ICT in learning (Sharpe et al., 2010).

The limitations of the rhetoric of worker/learner empowerment, then, are rooted in the complexities of work-related pressures and power dynamics at the local, organizational and institutional levels. In principle, educational and work-based environments have contrasting norms, activities, local orderings, goals and notions about performance, which will all have inherent pedagogical qualities (Billett, 2002; Engeström and Middleton, 1996 cited in Barab et al., 2004). When work and formal learning dimensions overlap, therefore, new configurations and dynamics are bound to evolve.

As a result, a more experience-based focus to pedagogy is needed - one in which wider dynamic interactions are explored (Ehlers, 2006). Such interactions, in fact, go beyond the local level. There is a complex interplay between human agency and institutional structures pursuing control, standardization and risk management (Creanor and Trinder, 2010). Instructional design is often contingent on wider contextual features emerging from the interaction of individual, organizational, market-based and institutional factors, which, in turn, condition local audiences' geographical distribution, goals, technical skills and facilities (Banathy and Jenlink, 2004; Barab et al., 2004; Shearer, 2003 cited in Gu, 2007). It follows that a more holistic understanding of multi-level dynamic interactions must also explore how different bodies of knowledge are sanctioned, how they are represented as meaningful and how technology is to be understood in respect to all this. 
A deeper exploration of user engagement, by extension, challenges a deterministic view of ICT instruments and an unproblematic notion of technology as given - as value-free ready-to use tools (Knorr Cetina, 1997; Orlikowski, 1993, 2000). Technologies are never neutral, 'embodying the intentions, desires, and views of those who created them' and reflecting 'a particular way of under- standing the world and formulating and solving problems' (Nicolini, 2006: 2755). The enacted practices of key players have a role in the ongoing constitution and change of technology in organizations (Giddens, 1984), and, as a result, computer-based objects are 'epistemic objects', which are continuously in transformation (Knorr Cetina, 1997). They function as 'boundary objects', articulating knowledge, meanings and work across communities, but are continuously reinterpreted and adapted by users in the various social worlds (Star and Griesemer, 1989). Moreover, technological artefacts are 'actants' themselves (Callon, 1986; Law, 1986), embodying symbolic meanings and material configurations that imply perceptions of learning, knowledge distribution, work practices, control and power dynamics (Bechky, 2003; Cacciatori, 2004; Fenwick, 2010; Fleischmann, 2006; Gasson, 2006; Hislop et al., 2000; Orlikowski, 2010). It follows that formalized e-learning in organizations is also affected by competing individual, organizational and institutional priorities, and different loci of power, accountability and control (Antonacopoulou, 2000; Antonacopoulou and Chiva, 2007). Therefore, a pedagogically informed exploration of e-learning needs to incorporate the notion of socially situated e-learning (Mayes and De Freitas, 2007).

This article will explore some of the unresolved issues highlighted in this 
review. For instance, what are the implications of the intermingling of work and formal learning for conceptualizations of an empowered learner and how are learning processes affected by contextual power dynamics? Moreover, to what extent might the blurring of the boundaries between structured learning and work bear upon learners understandings of instructional modes, content and tools, their motivations and their readiness for learning? Understandings of the context need to be extended from a strict focus on learning media to a more holistic conceptualization of what really matters as perceived and experienced by each learner.

\section{Methodology}

\section{The research questions}

Data collection and analysis are guided by an interpretive stance, aiming at a more complex under- standing of the learning context. Learner interpretations and enactments of systems, rules and procedures - and, in this case, structured learning programmes and tools - are assumed to have a direct impact on how they interact with the said e-learning tools. Moreover, it is assumed that learners' recursive interactions with their wider professional, social and contextual learning environment will be mediated by emerging symbolic meanings directly linked to power imbalances and dynamics within the specific organizational and institutional contexts.

This article explores, first, what respondents consider to be 'valuable' knowledge acquisition and learning processes. A second question is how they 
interpret and define the focal ICT system that mediates knowledge and learning, namely, their SDS. Finally, the study will explore local understandings and significance of learner empowerment in light of user engagement with the system.

\section{Data set and analysis technique}

The data set consists of 15 semi-structured face-to-face interviews focusing on respondent perceptions of their work experience (Joas, 1987). Respondents included core quantity surveyors and project managers, one consultant in the field of performance management, two knowledge management officers, two senior partners in charge of systems design and internal performance management and two senior human resources (HR) officers. Documentary data sources were also used, including (1) a set of notes and presentations used for young recruits induction; (2) a 'Survival Toolkit' aimed at new employees, listing web-based sources of information for staff; (3) an online recruitment web page; (4) a staff development appraisal form incorporating a competency frame- work; (5) performance management consultancy services sales pitch documents (PowerPoint presentation and report) and (6) other organizational web-based tools (for work and learning support and public relations (PR) orientation).

An interpretive, tailor-made tool based on cognitive mapping techniques was used for analysis. The approach merged causal mapping and argument mapping (Swan, 1997) by introducing a variety of communicative elements -

a technique different from that of more established mapping methods 
(Bougon, 1992; Brown, 1992; Cossette and Audet, 1992; Eden, 1992; Eden et al., 1992; Hoffmann, 2005; Jenkins, 1994; Langfield-Smith, 1992; Laukkanen, 1998). The use of maps enabled the representation of the recursive interaction between different moments and ideas within interviews, rather than treating respondents' discourses as linear. The introduction of different shapes and lines helped in the visualization of different modes of discourse, such as cause-and- effect relationships, stories, underlying assumptions or statements of value. Shapes also enabled the visual representation of overlapping, complementary and conflicting views at individual or group levels, avoiding a bias towards artificial consensus while enabling the identification of com- mon views and themes. The technique therefore allowed a more inclusive approach to group map- ping, valuing all respondents alongside each other, while emphasizing the individual maps of influential respondents.

It is also important to highlight that in this context, a 'cognitive mapping technique' is under- stood as distinct from the concept of 'cognitive maps'. The latter equate with mental models, while the former are map-like diagrams or devices to display representations of someone's thinking at a given time (Eden, 1992; Swan and Newell, 1994). A basic assumption is that the mapping of each script is informed by the respondents' context at the time of the interview. The tool is instrumental in revealing underlying values and conclusions that were not initially apparent in the linear script. Mapping, then, is not just about displaying, but is also about enabling and enhancing the interpretive analysis. Cognitive mapping analysis technique is coherent with the main tenets of SI (Prasad, 1993) and instrumental in revealing individuals' 
interpretations of their contexts at the time of interviews.

\section{Case description: QA Experts and the SDS}

\section{Company profile}

QA Experts is an international, multi-sector consultancy providing asset management services. They have 40 wholly owned offices worldwide, over 3000 staff and a $£ 200 m+$ turnover as a result of a period of growth via acquisitions. They offer quantity surveying services and therefore play a key role in building projects and the ongoing management of fixed assets. They manage the costs from early design plans through to a building's completion and beyond. Their focus is on ensuring that projects meet legal and quality standards and that clients get good value for money. They have expertise groups across a wide range of industries and types of services, including public, industrial, infrastructure and property sectors. They have had longterm relationships with a large pro- portion of their clients, some of which are globalized, multi-branch organizations. Most of their offerings have relatively low market differentiation and attract low profit margins, but the company has been developing higher profit margin service offerings that target existing clients with more innovative, client-specific consultancy services, such as performance management and client-centred performance benchmarking. Core activities are organized around teams, with overlap- ping geographical, sector- and service-specific dimensions.

Their learning and development programme is anchored in well-integrated HR 
management and project resourcing mechanisms, including a cascading performance management system that encompasses organizational, group and individual levels. Their blended approach to staff development includes faceto-face coaching and ICT-based training using their SDS, as well as mentoring and buddying schemes and classroom-based instruction for the graduate Assessment of Professional Competence (APC) programme. The APC aims to support graduates through the RICS accreditation scheme, providing practical training and specific on-the-job experience, which, when combined with academic qualifications, leads to prestigious RICS membership and chartered status. The whole APC process normally takes between 2 and 3 years. The training process continuously develops graduates' level of competency in whichever sector or service each is involved, and this determines their level of independence and exposure to client-facing duties. The competency levels range from Aware (describe but not deliver), to Basic (deliver with supervision), Competent (deliver independently), Distinguished (deliver and sell to a client) and, finally, Expert (deliver, sell, innovate and coach others). 'Expert', as well as being considered a level of expertise to which most workers aspire, is also the title of a formal position in the company. Experts in specific sectors or technical fields are well respected within the organization and provide great support for novice professionals - a process through which longer term informal mentoring relationships also tend to evolve.

\section{The SDS}

The SDS is an intranet-based tool introduced 6 years prior to the interviews. Following an intensive period of international acquisitions, the tool was conceived as a means to standardize procedures, documents and knowledge 
for the organization's 16 product lines across the corporation. Induction material states that sections of the system are 'owned' and updated with home-grown best practice by internal experts, but all users are encouraged to contribute ongoing feedback and suggest changes. The SDS is sometimes used as a training tool for more experienced new hires, as a support for familiarization with organizational practices; but its main de facto function nowadays is to provide a self-study tool for young graduates pursuing RICS accreditation.

In its function as a training tool for young graduates, the tool is well integrated with wider organizational systems. Completion of the modules contained in the SDS is self-paced, and progression is dependent on each individual's exposure to on-the-job responsibilities. Annual reviews, personal development plans and project resourcing are carried out in accordance with each individual's completion of training steps within the system. New hires are only allowed to take on client-facing projects once a satisfactory level of expertise has been achieved with respect to practice and completion of SDSbased modules. The system is supported by a cluster of documents and procedures, such as induction sessions, organizational 'toolkits' and initial expertise assessment procedures.

\section{Analysis}

\section{First question: local understandings of knowledge and learning}

The concept of learning in QA Experts is a faceted label, with some but not 
full conversion of interpretations. Perceptions of the SDS as a tool for learning - as discussed below - were directly conditioned not only by individuals' preferred modes of learning but also by socially constructed interpretations of valuable knowledge and ways of transferring and developing it.

Continuous learning, innovation and individual agency. Learning and knowledge derived from practice and problem-solving are central to staff's sense of self and professional ethics in this organization. For most respondents, value for customers is generated by each professional, who use their knowledge of industrial standards and creative problem-solving when faced with novel situations. This distinctive knowledge being continuously generated in practice is often labelled as innovation and 'better value for clients'. Creating value more cost-effective and productive assets - is everyone's responsibility:

I would say that there is almost a duty really on any [QA Experts] employee or manager or partner to make sure that we are continuously improving and innovating for our clients because otherwise the relationship would just die. (Anthony, Experienced Unit Leader)

The generation of innovation, or 'better value for clients', is perceived as intrinsically dependent on the upholding of industry-based and locally derived best practice standards. Standardization and innovation are not seen as dichotomous, but instead as mutually constitutive, or as a duality, as 
conceived by Giddens (1984). For staff at QA Experts, the recursive relationship between standardization and innovation is seen as the essence of their continuous learning process:

if you can think of ways of improving it (The SDS), you can tell 'Lee', and if they think it's better ... so, that's a form of innovation. That's open to everyone ... I don't think that standardization limits innovation. All these systems ... well, it is what people make of it, in the end of the day'. (Sandra, Early Career, Pursuing Chartered Status)

The SDS initially had a dual role in the recursive interactions between standardization and innovation, as respondents perceive it. Given that the practice of feeding back emerging procedural changes into the SDS was reenacted by the majority of core workers, the SDS acted as both medium and outcome (Giddens, 1984) of knowledge and best practice created in their everyday work.

That original dynamic interaction, however, has been changing in the last year, however, largely as a reaction to new company-sponsored messages trying to enforce the use of the SDS as mandatory, as discussed later on in this article.

Face-to-face learning, learning in practice and reflective learning. Another shared understanding is that learning by interacting with people is a superior mode of learning:

I think that's one of the reasons as a sector we are successful. It's the usual thing, it's the geographic link because we're sitting down talking all day long - those ideas are exchanged, and you learn with each other. 
(Rhys, Senior Chartered Surveyor)

In spite of the value attributed to structured and standardized performance of services, the power of the spoken rather than the written word prevails in this company. Whether by phone, personally, impromptu or as part of a preprogrammed web of meetings, people value and like to talk. Interaction with peers and experts is their chief means of learning and achieving better value for their clients. The highly regarded Experts open attitude to sharing and mentoring enables them to become much more influential than the SDS in the transmission of procedures, technical knowl- edge and professional values and standards:

There's always someone who's an oracle of knowledge around. And you do have to interact with other people. (Rhys, Senior Chartered Surveyor)

\section{Second question: local perceptions of the SDS as a tool for learning}

Views on ICT tools. Learning was often described as emerging from practice and human interactions, but there were also positive remarks on the use of ICT. The SDS was seen by some as a mediator between staff and experts in two main ways: as a central and visible, easily accessible depository of past experiences, and as an organizational 'Yellow Pages' for specific expertise. The SDS performs well as a tool for learning and for transferring lessons learned from one office to another for those who still see it as a continuously improving tool for respondents at all levels. However, an increasing proportion of core staff now see it as having stagnated. Among top management, nevertheless, there is still an idealized view of the SDS as a continuously evolving repository of knowledge. 
Wider views of the SDS as a tool for learning. Few respondents within the UK offices actually see the SDS as the voice of the Experts, but they do see the SDS as a second best to bring the Experts' knowledge to the newly acquired and geographically isolated units:

In our office we really learn by doing, through repetition, because we have a very high volume of similar types of projects. I think that if other, smaller or new offices use the SDS, they will probably reach a similar level of quality to ours. (Rhys, Senior Chartered Surveyor)

Few people now perceive that each of the SDS sections is actually authored and under the responsibility of an Expert. Similarly, fewer respondents believe that the SDS currently provides a true and fair view of the actual knowledge distributed and embedded across the organization. For most people, the SDS is a faceless system, far removed from practice. Moreover, there is increasing resistance towards the tool, since a corporate 'must use' message started to develop:

IT tools are not the experts - they cannot replace the 'oracles'. (Rhys, Senior Chartered Surveyor)

In fact, the SDS is perceived by many respondents as failing in its role as a tool for learning. A professional commitment to generating 'better value' for clients in practice and the unconditional belief in continuous improvement via 'talk' and interaction with more experienced professionals are nonnegotiable values held by most respondents: 
People may take a look at the SDS, but they use their superior for process guidance - which is what I do. (Emily, Chartered Quantity Surveyor)

IT tools de-humanize the learning experience. (Andre, Talent Development Manager)

The thing with learning and data systems is that learning requires asking the right questions. Data sheets may be misinterpreted and people might not ask the right questions about data sheets. (Emily, Chartered Quantity Surveyor)

As the SDS does not play a part in the actual performance of project work, it is not, therefore, associated with on-the-job learning processes. However, it is also true that trainees who have had insufficient opportunities for direct exposure to project experience also remain positive about the SDS as an important training tool.

\section{Third question: local understandings and significance of learner empowerment with respect to the SDS}

The practice of user engagement with continuous updating of the SDS is in theory still a core element of the tool's constitution. However, recent developments in the industry and in the organization have led to the fragmentation of the tool's functions. The SDS was described variously as a training tool, a knowledge management tool, an element of the performance 
management system, a repository for expert knowledge, a proof of 'better value' delivery and an element of a unique selling proposition. It has also recently been seen as a risk management tool, to be used as evidence for professional indemnity insurance:

more recently, it [the SDS] has helped us with our professional indemnity insurance ... Part of the risk of the insurance is how organised we are in what we do. (William, Group Systems Manager)

Officially, the SDS is described as a basic training, accreditation and competency-building instru- ment, and as a means to convey Experts and colleagues knowledge. At its inception, the process of generating the tool also functioned as a reflective learning exercise at organizational level:

The SDS was initially tested on the managers, and it revealed specific training needs. (William, Group Systems Manager)

... it helps with training, it helps us to understand where we are strong and where we are weak, but also. (William, Group Systems Manager)

The SDS covers $90 \%$ of what might occur in a process' and 'is the first place staff go to when learning how to do a new job. (Lucas, Knowledge Developer)

The quotes above, incidentally, were extracted from interviews with two of the SDS's original designers and reveal that they still see it as the ultimate benchmark for their core workers practice. In fact, in face of dwindling worker 
engagement with the SDS, they now feel the need to enforce its use on a continuous basis:

The systems were put in place, and people across the business were told: ... 'you will follow this process, or you're fired', basically. It's done mainly so we can bring our clients consistency. (Lucas, Knowledge Developer)

Nevertheless, it is unfair to restrict an appreciation of the SDS to those in power. Some non-mana- gerial staff who experienced the implementation of the SDS recognize its role in transferring locally produced knowledge and facilitating learning among an increasing number of subunits in a fast growing corporation:

... Before the SDS came in, all you could do if you wanted to write a letter or quote a report you'd turn round to the guy next to you and ask. I think when the SDS first came in, that was a replacement for the guy sitting next to you. It expanded the guy sitting next to you into all the guys sitting next to you anywhere in the world. (Rhys, Senior Chartered Surveyor)

The SDS as enabler of professional mobility. For young graduates, the SDS provides a means of pro- fessional development. Although they value up-tothe-minute knowledge and have an intrinsic belief in generating value for clients, it is also true that the SDS is seen by young recruits as a chan- nel for professional mobility from periphery to full community membership. RICS accreditation and client-facing duties are status milestones for them. The SDS, therefore, is perceived as a route to empowerment, and completion of 
the training process has acquired the symbolic role of a rite of passage, even if some of the new quantity surveyors have begun to doubt its usefulness in practice. A young recruit also attributed to the SDS the role of facilitating the blurring of hierarchical boundaries:

... you've got the old boys [here], and you have the people coming through ... a very much top-down approach ... has improved vastly through the SDS, through interaction and improving the graduate induction programme, making the partners aware that there are new people here, and that they have ideas too. (Sandra, Early Career, Pursuing Chartered Status)

The SDS is perceived by young quantity surveyors as a means to improve and show their proactive spirit. The completion of all modules after a 2- to 3year training process symbolizes a rite of passage for the young trainees. The role of the tool, in this case, takes on a much more personal perspective: learning and feeding back new knowledge, therefore, are not only about consensually agreed corporate goals of quality and customer satisfaction but also about more individually based interests in career progression and opportunities to obtain exposure within the organizational con- text. Similarly, young graduates interest in empowerment here is not about prioritizing their engagement with their own learning experience but seeking opportunities to climb the organizational ladder.

Exploring recursive interactions: agency, power and interpretive stances. QA Experts as a corporation espouses the notion of individual initiative, and every respondent felt responsible for generating new knowledge in practice, which 
explains the resentment felt towards the recent more authoritative 'must-usethe-SDS' discourse. Tight control - even where risk management and standardization are fully accepted - is a step too far: it clashes with people's sense of responsibility for the continuous improvement of the system.

For more experienced workers, therefore, empowerment is indeed about the co-production of their learning tools and processes. Their careers and selfconcept depend on continuous learning and, in their view, that can only happen effectively if they are allowed - and motivated - to populate the SDS with practice-derived new knowledge. Yet core professionals feel that this is not happening in practice. Perversely, the 'must use' stance is being interpreted as 'must not innovate, but follow what the [flawed] system dictates instead'.

Moreover, staff have also been very aware of their leaders' lack of engagement with the SDS. The SDS is an information-rich system, which is complex to navigate, and staff feel the need for leader brokerage in translating and appropriating the contents of the system to suit local group needs:

There's nobody in charge of highlighting important information contained in the SDS. I think it's the responsibility of the heads of sector to make sure the information in the SDS is used effectively ... (author's emphasis; Anthony, Experienced Unit Leader)

They also interpret leaders silence about the tool as lack of support for the continued enactment of the practice of feeding back new knowledge into the system: 
What's the latest, what's the most up to date? I think it's part of your line manager's role then to put the impetus onto you to say: Is it the best document that you can do? If it's not then when you finish what you believe is, you must then feed that back into the system. Perhaps that isn't encouraged enough or I think it is but it's not stressed enough here. (author's emphasis; Rhys, Senior Chartered Surveyor)

Beyond this, there is also the symbolic value of their internal Experts sanctioning. Expertise in this organization is a source of legitimacy - one respondent even uses the term 'oracle'. Most respondents believe that the company is a true meritocracy, and career progression is conditional on levels of knowledge and performance. Leaders and Experts, therefore, have strong referent power with respect to work-related practices. Their mediation and interpretation, if available, also serve as a token of approval, reinforcing the object's legitimacy.

The object's new mandatory status is starting to be interpreted by some as an indication that the SDS is being repositioned as a substitute for the 'oracles', but the SDS, 6 years after introduction, does not embody the knowledge of the well-respected Experts.

Ironically, and largely as a result of 'various professional interpretations', a negative recursive interaction is developing between users and their values, powerful factions and the content composition of the tool. Reduced feedback into the system undermines the tool's quality. Belief in the standardization/innovation duality as two interlaced elements of knowledge is 
a pivotal professional value, but the tool has not been updated effectively by users or even some Experts. At the moment, it is perceived neither to incorporate up-to-date industrial standards nor to be flexible enough to incorporate new knowledge as it is acquired in practice and that results in further diminished use and even less commitment to engage in updating the tool.

Top management has also lost interest in the SDS as a tool for organizational learning, despite their focus on using it as evidence of risk management. Top management priority for organizational knowledge has shifted towards automatic data capture, which is not supported by the SDS. The SDS, therefore, has not inspired either old or new change-thirsty knowledge management officers in charge of taking the organization 'forwards' to 'the next level' - which bodes ill for the tool's centrality in the future. The one powerful factor that remains positively associated with the SDS is the RICS and its accreditation system, which nevertheless applies specifically to new graduates.

\section{Discussion}

\section{The SDS from a pedagogical perspective}

Learner empowerment, motivation and instructional tool features. Dwindling engagement with the SDS is conditioned by a number of contextual phenomena, which interact recursively with learners' preferred modes of learning and their need to be involved as co-producers of the learning 
experience (Dewald, 2003; Ehlers, 2006; Knowles, 1995).

Within this organizational context, power dynamics play a clear role. The counterproductive impact of the new 'must-use-the-SDS' discourse interpreted as a decree for knowledge closure - may have outcomes beyond the organizational dynamics dimension. Knowledge repositories and benchmarked blueprints for action, often intended as tools for control at a distance (Latour, 1987) or for the sanctioning of practices, may unintentionally fail as training tools from a cognitive and pedagogical perspective. In the SDS's case, attitudes and expectations towards using and co- producing the tool are driven by competing strategic and professional interpretations of valuable knowledge. Pedagogically inspired preoccupations over effective learning processes, preferred modes of learning and specific learner backgrounds have not played a part in instructional design in this case.

That is not to say, however, the design of the tool has totally failed from a pedagogical perspective. For instance, an element highlighted by Govindasamy (2002) is task analysis, which determines the appropriate depth of content and amount of detail, taking into consideration what learners should be able to perform and desired standards of performance. With respect to the SDS as a graduate training tool, it can be said that trainees' qualifications have been considered carefully. The tool supports the natural evolution of quantity surveyors professional development, clearly addressing specific types of skills and levels of capability. Personal learning needs are respected in that the various modules can be completed alongside coherently allocated project roles, supported by a personal development plan and mentoring. As a result, a variety of instructional methods is applied. In 
general, however, the restricted technical features of the SDS hinder its ability to cater for different learning needs, and the tool fails to incorporate potential innovations in emerging technologies with respect to reciprocity, dialogic reflection and a processual focus (Hughes, 2010).

Of greater consequence, however, is the attempt to achieve maximum tool flexibility with respect to its functions and target audience. The tool was used in three main ways. First, it was aimed at young quantity surveyors studying for chartered examinations, and learning patterns were conditioned by a tightly controlled route. Second, new but more experienced recent recruits who were not pursuing chartered accreditation were given greater flexibility in navigating the system, with the proviso that all the sections must have been covered before client-facing duties were initiated. Finally, all other professionals were, in principle, free to use the tools if and when work-related problems demanded. Given such a contrasting profile of target users, it is not surprising that the clarity of instructional objectives has been compromised. As a training tool for new recruits, partial and long-term objectives are clearly and coherently set. When the training function of the tool starts to overlap with a knowledge- and process-standardizing dimension aimed at practitioners at other levels, objectives become increasingly unclear and contested. Although modularity and hyperlink architecture are desirable etool features (Shapiro and Niederhauser, 2004), the attempt to engage with users of different professional status and degrees of experience has had unintended and unexpected consequences for the continuous updating and perceived legitimacy of the tool.

The existence of multiple audiences also exacerbates the complexity of 
recursive design evaluation processes by all pertinent stakeholders (Govindasamy, 2002). With regard to the SDS, it emerges that there has been no formal element of expert, learner and specific group evaluation since the tool's implementation phase. Experts assumed ownership of specific modules and users' volunteered changes to information in the system had previously been used as practice-based proxies for formal periodic re-evaluation of the tool. This has faltered as Experts and users alike have failed to update the system consistently, and the tool itself does not provide an inbuilt mechanism for continuous user evaluation and adaptation.

What has become clear in this discussion so far is that many of the pedagogically informed concepts explored in the literature prove pertinent to user engagement with the tool in this case. Such factors, however, are inextricably conditioned by the social dimension (Macpherson et al., 2004) and, in particular, by symbolic meanings emerging from social interactions between humans and artefacts, as discussed below.

SI, work-based learning and the SDS. Power and legitimacy are intimately interconnected in practice (Hallett, 2003), and in the case of the SDS, legitimacy of knowledge is pivotal. 'Power to define the situation' in this case relates directly to professionals views on what valuable knowledge is and how it is to be acquired. In this case, valuable knowledge is embodied by continuous improvement generated in practice, which equates with innovation. 'Better value' knowledge, therefore, is never crystallized. It evolves through problem-solving and recursively interacting with local and 
industrial procedural standards. Recursiveness between standardization and innovation, however, is non-negotiable, which explains why non-managerial respondents distanced themselves from the new organizational discourse of compliance with SDS-based canonical models and practices (Brown and Duguid, 1991). Moreover, the competition and complementarities between various sources of meanings are significant. A number of elements contribute to core workers constructs of valid knowledge: learners prior understandings of what their profession entails; internal training materials and PR documents; interactions with peers, superiors and Experts in problem-solving and RICS-derived benchmarks and examinations. It cannot be said, therefore, that one specific actant has the power to define valuable knowledge. Even the Experts, who at first glance appear to exert the strongest influence on professional values and behaviours, are affected by ongoing interactions among the various actants over the years.

Furthermore, it is misleading to conceptualize professionals within the organization as one homogeneous block. For instance, although the RICS as an intermediate institution (Stryker, 2008) is well respected by all professionals in the organization, RICS accreditation only has primacy in young graduates' personal development. From the perspective of young graduates, the SDS borrows its legitimacy as a training tool from RICS. However, post-accreditation workers have a much diminished perception of SDS's legitimacy as a medium for learning. When the 'must use' discourse was introduced, they started to perceive a strong degree of competition rather than complementarity - between the SDS and the Experts as sources of knowledge. 
The Experts themselves have become a social object, in that they represent what all lower ranking professionals aspire to be: individuals who merit high status in the organization by providing true better value to clients and who generously feed practice-generated knowledge back into the system, meeting up with new recruits and other colleagues in the various subunits. SDS's legitimacy began to be undermined from the moment when SDS-based knowledge and Expert-imparted knowledge started to compete in the minds of the professionals.

Experienced core workers in this organization could not possibly identify with the SDS in the same way as they identify with the Experts, in particular, because the knowledge crystallized in the system is stale and is increasingly perceived to deny their right to agency and innovation. Generating practicederived continuous improvement is inherent to the identity of quantity surveyors: when the SDS was seen to enable them to do this, it was perceived as congruent with their identity work (Watson, 2008). When the SDS started to be perceived as less malleable for incorporating new knowledge, it began to be redefined negatively (Charon, 2001), amid ongoing interactions and local leaders silence about the tool. Furthermore, identity work includes making choices over rela- tionships, situations and local cultures (Fine, 1993). Disengaging with the SDS was never about lack of time or forgetfulness - it was a choice that was necessary to protect self-identity. As part of that identity work, individuals are 'talking to self' and communicating to their peers their allegiance to the Experts instead (Charon, 2001: 44-49).

A final consideration relates to Stryker's (2008) conceptualization of parts of the self as some- times conflicting and sometimes independent of one another. 
It became clear that given the role of knowledge in the quantity surveyors' identity work, their worker and learner personas are inevitably interwoven. This means, in turn, that it is a fallacy to assume that any learning tool or process being developed within this context can ever be conceived as neutral

or divorced from work processes. Organizational power imbalances and discourses, alongside professional and work-based values, identities and status boundaries all work in conjunction to sanction specific learning goals, processes and approaches. As a result, e-learning tools are overloaded with symbolic meanings, which, in this case, by most accounts contribute to the undermining of the tool. The SDS's original legitimacy was achieved because it had effectively enabled the articulation of knowledge across organizational units. Now, its impending demise is largely linked to an increasing perception of flaws in its work-related role. The shifting organizational ecology - driven by various actors - has weakened the tool's legitimacy and, ultimately, its ability to effectively engage and enrol a greater proportion of professionals (Callon, 1986).

\section{Conclusions and implications}

This study has reinforced the conceptualization of work and training-oriented ICT tools as symbolic artefacts (Swan et al., 2007). Moreover, it has shown that socially sanctioned understandings of knowledge and modes of learning are also significant for ongoing interactions and self-identities. The perceived legitimacy of e-training tools contributes to individual learners identity work and is framed by socially constructed understandings of valuable knowledge 
and socially acceptable modes of learning. Emerging negotiated orders of what to learn, how to learn and how valuable knowledge should be leveraged, moreover, develop against the backdrop of influential institutional players, such as industry-based accreditation institutes and official auditors. The learning context, therefore, emerges as much more complex and modulated than most pedagogically driven studies have assumed. Findings in this case have implications both for the practice of e-learning design and for theoretical conceptualizations within SI as a framework for organizational research.

With respect to the practice of e-learning design, tensions between work and learning pose a dilemma for designers of training initiatives. On the one hand, developments in this case show that attempts to use the same information technology (IT) tool to satisfy multiple purposes may actually lead to confusion and ineffectiveness (McHenry and Strønen, 2008). On the other hand, however, the case also shows that the very identification of the tool with the work dimension secured its initial legitimacy. If what matters for learning in the workplace is engagement with real problems (Gibb, 1997; Sadler-Smith et al., 2000), then a tool for learning might actually gain acceptance by being also a tool for problem-solving. ICT media can be productive instruments in supporting learning through doing (Knowles, 1990; Kolb, 1984), provided they are well integrated into a wider system for individual and organizational development (Sadler-Smith et al., 2000). Yet it is not enough to superimpose a training function on tools that have originally been devised with knowledge management in mind. The context and tools for work-based e-learning and training processes need to be addressed in their own right (Tynjälä and Häkkinen, 2005), with respect to 
practice and research. Much more pedagogically informed research is needed to explore this in depth, and greater consideration for the local learning and working context must support the design of such training instruments and initiatives. Notwithstanding criticisms of a purely technical view of elearning (Easterby-Smith and Araujo, 1999; O’Reilly, 2000), it emerges that research into e-learning in organizations should not be focusing less on technology issues but, rather, should embrace technology as part of a richer dialogue between pedagogy and sociology. Findings in this case also have implications for the symbolic interactionist conceptualization of individual multiple identities and respective commitments (Stryker, 2008) specifically with respect to potential tensions and interactions between individuals worker and learner identities. Here, the assumption that rolebased identities are activated by interactional commitments (Stryker, 2008) is not helpful in explaining the learner/worker relationship. The two dimensions need to be conceived as a duality (Giddens, 1984) rather than a dichotomy. This article conceptualizes individual learner and worker personas as recursively evolving and mutually constitutive. Against a background where workers are expected to manage their own career development and employability (May et al., 2002), learning and training become deeply intertwined with professionals' own future prospects and self-concept, albeit necessarily mediated by wider sociocultural and institutional forces. Exploring worker/learner identity interactions represents a further step towards understanding how professionals continuously manipulate a variety of social objects to recreate desired conceptions of their own work, knowledge status and identity. This will also shed light on processes, resulting in a more durable sedimentation of what constitute legitimate practices and 
knowledge within a specific professional field.

\section{Acknowledgements}

I would like to thank the respondents in this study for their time, trust and support. I am also grateful to Davide Nicolini and the anonymous reviewers for their valuable comments and insights on earlier drafts of this paper.

\section{Funding}

This research received no specific grant from any funding agency in the public, commercial, or not-for- profit sectors. 
References

Alavi M and Gallupe RB (2003) Using information technology in learning: Case studies in business and management education programs. Academy of Management Learning \& Education 2: 139-153.

Alvesson M and Kärreman D (2001) Odd couple: Making sense of the curious concept of knowledge management. Journal of Management Studies 38(7): 995-1018.

Antonacopoulou E (2000) Employee development through self-development in three retail banks. Personnel Review 29(4): 491-508.

Antonacopoulou E and Chiva R (2007) The social complexity of organizational learning: the dynamics of learning and organizing. Management Learning 38(30): 277-295.

Banathy BH and Jenlink PM (2004) Systems inquiry and its application. In: Jonassen DH (ed.) Handbook of Research on Educational Communications and Technology. 2nd edn. Mahwah, New Jersey: Lawrence Erlbaum Associates, pp. 37-57.

Barab SA, Evans MA and Baek E (2004) Activity theory as a lens for characterizing the participatory unit. In: Jonassen DH (ed.) Handbook of Research on Educational Communications and Technology. 2nd edn. Mahwah, New Jersey: Lawrence Erlbaum Associates, pp. 199-214. 
Barley SR and Tolbert PS (1997) Institutionalization and structuration: Studying the links between action and institution. Organization Studies 18: 93-117.

Bechky B (2003) Object lessons: Workplace artefacts as representations of occupational jurisdiction. American Journal of Sociology 109(3): 720752.

Beetham H and Oliver M (2010) The changing practices of knowledge and learning. In: Sharpe R, Beetham H and De Freitas S (eds) Rethinking Learning for a Digital Age: How Learners Are Shaping Their Own Experiences. New York and Abingdon: Routledge, pp. 155-169.

Bijker WE, Hughes TP and Pinch TJ (1987) The Social Construction of Technological Systems. Cambridge, MA: MIT Press.

Billett S (2002) Critiquing workplace learning discourse: Participation and continuity at work. Studies in the Education of Adults 34(1): 56-67.

Blumer H (1969) Symbolic Interactionism: Perspective and Method. Englewood Cliffs, NJ: Prentice Hall. Bougon MG (1992) Congregate cognitive maps: A unified dynamic theory of organization and strategy.

Journal of Management Studies 29(3): 369-389.

Brown JS and Duguid P (1991) Organizational learning and communities-ofpractice: Towards a unified view of working, learning, and innovation. Organization Science 2(1): 40-57. 
Brown S (1992) Cognitive mapping and repertory grids for qualitative survey research: Some comparative observations. Journal of Management Studies 29(3): 288-307.

Cacciatori E (2004) Organizing Memory for Innovation in Project Environments - Collaboration and Conflict in the Construction of Competencies. New Orleans, LA: Academy of Management Meeting.

Callon M (1986) Some elements of a sociology of translation: Domestication of the scallops and the fisher- men of St Brieuc Bay. In: Law J (ed.) Power, Action and Belief. London: Routledge and Kegan Paul, pp. 196-223.

Carr-Chellman A and Savoy M (2004) User-design research. In: Jonassen DH (ed.) Handbook of Research on Educational Communications and Technology. 2nd edn. Mahwah, New Jersey: Lawrence Erlbaum Associates, pp. 701-716.

Charon JM (2001) Symbolic Interactionism: An Introduction, An Interpretation, An Integration. 7th edn. London: Prentice Hall International.

Cossette P and Audet M (1992) Mapping of an idiosyncratic schema. Journal of Management Studies 29(3): 325-347.

Creanor L and Trinder K (2010) Managing life and study with technology. In: Sharpe R, Beetham H and De Freitas S (eds) Rethinking Learning for a Digital Age: How Learners Are Shaping Their Own Experiences. New York and Abingdon: Routledge, pp. 43-55.

Czerniewiecz L and Brown C (2010) Strengthening and weakening 
boundaries - Student negotiating technology mediated learning. In: Sharpe R, Beetham H and De Freitas S (eds) Rethinking Learning for a Digital Age: How Learners Are Shaping Their Own Experiences. New York and Abingdon: Routledge, pp. 142-152.

Dewald NH (2003) Pedagogy and andragogy. In: Dupuis EA (ed.) Developing Web-Based Instruction: Planning, Designing, Managing, and Evaluating for Results. London: Facet Publishing, pp. 47-68.

Easterby-Smith M and Araujo L (1999) Current debates and opportunities. In: Easterby-Smith M, Araujo L and Burgoyne J (eds) Organizational Learning and the Learning Organization: Developments in Theory and Practice. London: SAGE, pp. 1-22.

Eden C (1992) On the nature of cognitive maps. Journal of Management Studies 29(3): 261-265.

Eden C, Ackermann F and Cropper S (1992) The analysis of cause maps. Journal of Management Studies, 29(3): 309-324.

Ehlers U (2006) Myths and realities in learner oriented e-learning-quality. In: Ehlers UD and Pawlowski JM (eds) Handbook on Quality and Standardisation in E-Learning. Berlin/Heidelberg: Springer, pp. 367-387. Engeström Y and Middleton D (1996) Cognition and Communication at Work. Cambridge: Cambridge University Press, pp. 1-15.

Fenwick T (2010) Re-thinking the 'thing' - Sociomaterial approaches to understanding and researching learning in work. Journal of Workplace Learning 22(1/2): 104-116. 
Fine GA (1992) Agency, structure and comparative contexts: Towards a synthetic interactionism. Symbolic Interaction 15(1): 87-107.

Fine GA (1993) The sad demise, mysterious disappearance, and glorious triumph of symbolic interactionism. Annual Review of Sociology 19: 61-87.

Fleischmann KR (2006) Boundary objects with agency: A method for studying the design-use interface. Information Society 22: 77-87.

Francis G and Holloway J (2007) What have we learned? Themes from the literature on best-practice benchmarking. International Journal of Management Reviews 9(3): 171-189.

Fresina AJ (1997) Corporate universities can - and should - be typed according to their missions. Is yours a reinforcer, change manager or shaper? Corporate University Review 5(1): 3-13.

Gasson S (2006) A genealogical study of boundary-spanning IS design. European Journal of Information Systems 15(1): 26-41.

Gibb AA (1997) Small firms training and competitiveness: Building upon the small firm as a learning organi- zation. International Small Business Journal 15(3): 13-29.

Giddens A (1984) The Constitution of Society. Cambridge: Polity Press.

Goffman E (1959) The Presentation of Self in Everyday Life. Garden City, NY: Anchor Books.

Good M (2001) On the way to online pedagogy. In: Stephenson J (ed.) 
Teaching and Learning Online. London: Kogan Page, pp. 165-174.

Goodyear P and Ellis RA (2010) Expanding conceptions of study, context and educational design. In: Sharpe R, Beetham $\mathrm{H}$ and De Freitas $\mathrm{S}$ (eds) Rethinking Learning for a Digital Age: How Learners Are Shaping Their Own Experiences. New York and Abingdon: Routledge, pp. 100-114.

Govindasamy $T$ (2002) Successful implementation of e-learning: Pedagogical considerations. Internet and Higher Education 4(1): 287-299.

Grant RM (1996) Toward a knowledge-based theory of the firm. Strategic Management Journal (Special Issue: Knowledge and the Firm) 17: 109-122.

Gu Y (2007) Learning by multimedia and multimodality: Some critical reflections on web-based courseware Design in the Chinese context. In: Spencer-Oatey H (ed.) E-Learning Initiatives in China: Pedagogy, Policy and Culture. Hong Kong: Hong Kong University Press, pp. 37-55.

Hallett T (2003) Symbolic power and organizational culture. Sociological Theory 21(2): 128-149.

Hallett T, Shulman D and Fine GA (2010) Peopling organizations - The promise of classic symbolic interactionism for an inhabited institutionalism. In: Adler PS (ed.) The Oxford Handbook of Sociology and Organization Studies. Oxford: Oxford University Press, pp. 486-509.

Haythornthwaite C (2000) Online personal networks: Size, composition, and media use among distance learners. New Media \& Society 2(2): 195-226. 
Hewitt JP (2007) Self and Society - A Symbolic Interactionist Social Psychology. 10th edn. Boston, MA: Pearson Education Inc.

Hislop D, Newell S, Scarbrough H, et al. (2000) Networks, knowledge and power: Decision making, politics and the process of innovation. Technology Analysis \& Strategic Management 12(3): 399-411.

Hoffmann M (2005) Logical argument mapping: A method for overcoming cognitive problems of conflict management. International Journal of Conflict Management 16(4): 304-334.

Hughes EC (1951) Work and the self. In: Rohrer JH and Sherif M (eds) Social Psychology at the Crossroads. New York: Harper \& Brothers, pp. 313-323.

Hughes J (2010) But it's not just developing like a learner, it's developing as a person - Reflections on e-portfo- lio-based learning. In: Sharpe R, Beetham H and De Freitas S (eds) Rethinking Learning for a Digital Age: How Learners Are Shaping Their Own Experiences. New York and Abingdon: Routledge, pp. 199-211.

Illeris K (2003) Forum: Workplace learning and learning theory. Journal of Workplace Learning 15(4): 167-178. Jenkins M (1994) A methodology for creating and comparing strategic causal maps. Cranfield School of Management. Working Papers Series SWP 2/94. Available at: //dspace.lib.cranfield.ac.uk/bit-stream/1826/565/2/SWP0294.pdf

Joas H (1987) Symbolic interactionism. In: Giddens A and Turner JH (eds) Social Theory Today. Cambridge: Polity Press, pp. 82-115. 
Jung I and Rha I (2000) Effectiveness and cost effectiveness of online education: A review of the literature. Educational Technology, July-August 2000, 57-61.

Knorr Cetina K (1997) Sociality with objects: Social relations in postsocial knowledge. Theory Culture \& Society 14(4): 1-30.

Knowles MS (1990) The Adult Learner: A Neglected Species. Houston, TX: Gulf Pub Co.

Knowles MS (1995) Designs for Adult Learning. Alexandria, VA: American Society for Training and Development.

Kolb DA (1984) Experiential Learning. Englewood Cliffs, NJ: Prentice Hall.

Koschmann T (1996) CSCL: Theory and Practice of an Emerging Paradigm. Mahwah, NJ: Lawrence Erlbaum Associates.

Lahn LC (2004) Dilemmas in the development of e-learning at work. Journal of Workplace Learning 16(8): 466-478.

Lamertz K, Martens M and Heugens P (2003) Issue evolution: A symbolic interactionist perspective. Corporate Regulation Review 6(1): 8293.

Langfield-Smith K (1992) Exploring the need for a shared cognitive map. Journal of Management Studies 29(3): 349-368.

Latour B (1987) Science in Action. Cambridge, MA: Harvard University 
Press.

Laukkanen M (1998) Conducting causal mapping research: Opportunities and challenges. In: Eden C and Spender JC (eds) Managerial and Organizational Cognition: Theory, methods and research. London: SAGE, pp. 168-191.

Lave J (1988) Cognition in Practice: Mind, Mathematics, and Culture in Everyday Life. New York: Cambridge University Press.

Law J (1986) On the methods of long-distance control: Vessels, navigation and the Portuguese route to India. In: Law J (ed.) Power, Action and BeliefA New Sociology of Knowledge? London: Routledge and Kegan Paul, pp. 234-263.

McHenry J and Strønen F (2008) The trickiness of IT enhanced competence management. Journal of Workplace Learning 20(2): 114-132.

Macpherson A, Elliot M, Harris I, et al. (2004) E-learning: Reflections and evaluation of corporate programmes. Human Resource Development International 7(3): 295-313.

Macpherson A, Homan G and Wilkinson K (2005) The implementation and use of e-learning in the corporate university. Journal of Workplace Learning 17(1/2): 33-48.

Maule R (1997) Adult IT programs: A discourse on pedagogy and strategy on the internet. Internet Research: Electronic Networking Applications and Policy 7(2): 129-152. 
May TYM, Korczynski M and Frenkel S (2002) Organizational and occupational commitment: Knowledge workers in large corporations. Journal of Management Studies 39(6): 775-801.

Mayes T and De Freitas S (2007) Learning and e-learning. In: Beetham H and Sharpe R (eds) Rethinking Pedagogy for a Digital Age. New York and Abingdon: Routledge, pp. 13-25.

Mead GH (1934) Mind, Self and Society. Chicago, IL: University of Chicago Press.

Musolf GR (1992) Structure, institutions, power, and ideology: New directions within symbolic interaction- ism. Sociological Quarterly 33(2): 171-189.

Netteland G, Wasson B and Mørch A (2007) E-learning in a large organization - A study of the critical role of information sharing. Journal of Workplace Learning 19(6): 392-411.

Nicolini D (2006) The work to make telemedicine work: A social and articulative view. Social Science \& Medicine 62: 2754-2767.

Nicolini D and Meznar M (1995) The social construction of organizational learning: Conceptual and practical issues in the field. Human Relations 48(7): $727-746$.

Oliver R, Harper B, Wills S, et al. (2007) Describing ICT-based learning designs that promote quality learn- ing outcomes. In: Beetham $\mathrm{H}$ and Sharpe R (eds) Rethinking Pedagogy for a Digital Age. New York and Abingdon: 
Routledge, pp. 64-80.

O’Reilly S (2000) Man and machine in harmony. Training, September 2000, pp. 114-117.

Orlikowski W (1993) CASE tools as organizational change: Investigating incremental and radical changes in systems development. MIS Quarterly 17(3): 309-340.

Orlikowski W (2000) Using technology and constituting structures: A practice lens for studying technology in organizations. Organization Science 11(4): 404-428.

Orlikowski W (2010) The sociomateriality of organisational life: Considering technology in management research. Cambridge Journal of Economics 34: $125-141$.

Prasad P (1993) Symbolic processes in the implementation of technological change: A symbolic interactionist study of work computerization. Academy of Management Journal 36(6): 1400-1429.

Reynolds M (1997) Learning styles: A critique. Management Learning 28(2): 115-133.

Rovai A (2002) Sense of community, perceived cognitive learning, and persistence in asynchronous learning networks. Internet and Higher Education 5: 319-332.

Rumble G (2001) Re-inventing distance education, 1971-2000. International 
Journal of Lifelong Education 20(1/2): 13-43.

Sadler-Smith E, Down S and Lean J (2000) Modern 'learning' methods: Learning and reality. Personnel Review 29(4): 474-490.

Salmon G (2000) E-Moderating: The Key to Teaching and Learning Online. London: Kogan Page. Sandelands E and Wills M (1996) Creating virtual support for lifelong learning. The Learning Organization 3(5): 26-31.

Scheff TJ (2005) Looking-glass self: Goffman as symbolic interactionist. Symbolic Interaction 28(2): 147-166.

Shapiro A and Niederhauser D (2004) Learning from hypertext: Research issues and findings. In: Jonassen $\mathrm{H}$ (ed.) Handbook of Research on Educational Communications and Technology. 2nd edn. Mahwah, New Jersey: Lawrence Erlbaum Associates, pp. 605-620.

Sharpe R and Beetham H (2010) Understanding students' uses of technology for learning: towards creative appropriation. In: Sharpe R, Beetham $\mathrm{H}$ and De Freitas S (eds) Rethinking Learning for a Digital Age: How Learners Are Shaping Their Own Experiences. New York and Abingdon: Routledge, pp. 85-99.

Sharpe R and Oliver M (2007) Supporting practitioners' design for learning. In: Beetham H and Sharpe R (eds) Rethinking Pedagogy for a Digital Age. New York and Abingdon: Routledge, pp. 117-127. 
Sharpe R, Beetham H and de Freitas S (2010) An introduction. In: Sharpe R, Beetham H and De Freitas S (eds) Rethinking Learning for a Digital Age: How Learners Are Shaping Their Own Experiences. New York and Abingdon: Routledge, pp. 1-12.

Shearer R (2003) Instructional design in distance education: An overview. In: Moore MG and Anderson WG (eds) Handbook of Distance Education. Mahwah, New Jersey: Lawrence Erlbaum Associates, pp. 275-286.

Smith M and Newman A (1999) How to create a virtual learning community. Training and Development 53(7): 44-48.

Sparrow S (2000) On-line learning faces an uphill struggle. Training Magazine, October 2000, pp. 20-21.

Sparrow S (2001) Intranets have impact. Training Magazine, October 2001, pp. 20-22.

Star SL and Griesemer J (1989) Institutional ecology, 'Translations' and boundary objects: Amateurs and professionals in Berkeley's museum of vertebrate zoology, 1907-39. Social Studies of Science 19: 387-420. Strauss A, Schatzman L, Ehrlich D, et al. (1963) The hospital and its negotiated order. In: Freidson E (ed.) The Hospital in Modern Society. New York: Free Press, pp. 147-169.

Stryker S (1968) Identity salience and role performance: The relevance of symbolic interaction theory for family research. Journal of Marriage and Family 30: 558-564. 
Stryker S (2008) From mead to a structural symbolic interactionism and beyond. Annual Review of Sociology 34: 15-31.

Swan J (1997) Using cognitive mapping in management research: Decisions about technical innovation. British Journal of Management 8: 183-198.

Swan J and Newell J (1994) Managers' beliefs about factors affecting the adoption of technological innovation: A study using cognitive maps. Journal of Managerial Psychology 9(2): 3-11.

Swan J, Bresnen M, Newell S, et al. (2007) The object of knowledge: The role of objects in biomedical inno- vation. Human Relations 7(2): 225-246.

Tynjälä P and Häkkinen P (2005) E-learning at work: Theoretical underpinnings and pedagogical challenges. Journal of Workplace Learning 17(5/6): 318-336.

Watson TJ (2008) Managing identity: Identity work, personal predicaments and structural circumstances. Organization 15(1): 121-143.

Weick K (1979) The Social Psychology of Organizing. Reading, MA: Addison-Wesley.

Welsh ET, Wanberg CR, Brown KG, et al. (2003) E-learning: Emerging uses, empirical results and future directions. International Journal of Training and Development 7(4): 245-258. 
